\title{
Erratum to: SOCRATIC, the Place Where Social Innovation 'Happens'
}

\author{
SOCRATIC Consortium, Inés Romero ${ }^{1}$, Yolanda Rueda ${ }^{1(\bowtie)}$, \\ Antonio Fumero ${ }^{1}$, Thomas Vilarinho ${ }^{2}$, Jacqueline Floch ${ }^{2}$, \\ Manuel Oliveira ${ }^{3}$, and Inès Dinant ${ }^{4}$ \\ ${ }^{1}$ Fundación Cibervoluntarios, Project Management Office, Madrid, Spain \\ \{ines. romero, yolanda. rueda, \\ antonio.fumero\}@cibervoluntarios.org \\ 2 SINTEF Digital, Trondheim, Norway \\ 3 SINTEF Technology and Society, Trondheim, Norway \\ ${ }^{4}$ Farapi Evidentis, Donostia/San Sebastián, Spain
}

\section{Erratum to: \\ Chapter "SOCRATIC, the Place Where Social Innovation 'Happens"' in: F. Bagnoli et al. (Eds.): \\ Internet Science, LNCS, DOI: 10.1007/978-3-319-45982-0_8}

In a previously published version of this paper, the names of the members of the SOCRATIC Consortium were missing. This has been updated.

SOCRATIC Consortium Members: Inés Romero, Fundación Cibervoluntarios, Project Management Office, Madrid, Spain; Rueda, Fundación Cibervoluntarios, Project Management Office, Madrid, Spain; Antonio Fumero, Fundación Cibervoluntarios, Project Management Office, Madrid, Spain; Thomas Vilarinho, SINTEF Digital, Trondheim, Norway; Jacqueline Floch, SINTEF Digital, Trondheim, Norway; Manuel Oliveira, SINTEF Technology and Society, Trondheim, Norway; Inès Dinant, Farapi Evidentis, Donostia/San Sebastián, Spain.

The updated online version of this chapter can be found at http://dx.doi.org/10.1007/978-3-319-45982-0_8 